\title{
Cost control of out-of-hours laboratory services in district general hospitals
}

\author{
K D Allen
}

\begin{abstract}
Aims-To survey methods for cost control of out-of-hours laboratory services in district general hospitals in England and Wales.

Methods-A questionnaire was distributed to 66 district general hospital laboratories in England and Wales.

Results-The response rate was $61 \%$. Most laboratories for which budgetary information was provided had on-call costs ranging between $10-21 \%$ of staff costs. Ninety five per cent of respondents had attempted to reduce workload by the use of various strategies. Seventy two per cent of responding laboratories had negotiated a wide variety of on-call agreements outside Whitley Council arrangements. Seventy two per cent were not satisfied with their on-call arrangements, the main desired objective being the introduction of the extended working day.

Conclusions-From this study it seems that Whitley Council agreements for outof-hours work are no longer appropriate for the average district general hospital laboratory. Workload reduction strategies should include the use of a limited list, audit of the use of the on-call service, and continued education of medical stafi. Consideration may also be given to the introduction of fixed payments, extension of the working day, increased multidisciplinary on-call and increased bedside testing.
\end{abstract}

(F Clin Pathol 1994;47:782-786)

NHS pathology services cost about $£ 333$ million a year, or $3 \%$ of the total hospital and community services budget. ${ }^{1}$ Therefore, it has been argued that small savings in budgets at a local level could produce appreciable savings nationally. ${ }^{23}$

The current provision of out-of-hours

Correspondence to:

Dr K D Allen

Accepted for publication 28 February 1994 service is governed by Professional and Technical Staff B (PTB) Whitley Council agreements. These arrangements were first introduced in 1951 and include standby and call payments. A call was defined in 1970 as a two hour period and this arrangement has remained ever since, despite advances in automation which mean that many tests can be completed within 10 minutes. In addition, the change from multidisciplinary to single discipline on-call has resulted in increased costs. There has also been a phenomenal increase in the number of investigations requested out-of-hours, partly due to advances in treatment but also due to an increase in the numbers of inappropriate requests, possibly due to fear of litigation..$^{4-8}$

Reduction of costs may involve two different approaches. Reduction of the workload may be achieved by the use of a limited list, ${ }^{9}$ education of clinical staff, ${ }^{70-14}$ provision of on-call guidelines, ${ }^{515-18}$ audit of the use of the on-call services, ${ }^{7} 1012$ provision of cost information to clinicians, ${ }^{2121719-21}$ clinical budgeting, use of bedside testing ${ }^{22-24}$ and screening of calls by medical laboratory staff. ${ }^{25}$ Another approach to reduction of on-call costs is to change the work and payment systems of the on-call services - for example, introduction of multidisciplinary on-call, ${ }^{1}$ fixed payments, ${ }^{26} 27$ centralisation, extended working day and week, time off in lieu, annual hours agreements, ${ }^{28}$ and competitive tendering.

\section{Methods}

In February 1993, questionnaires were sent to 66 district general hospital laboratories in England and Wales. The questionnaire explored strategies for reducing the workload, current on-call systems, costs and payments. Workload statistics were not requested because it was felt that the varying definitions of patient request and the variety of workload measurements would not allow for accurate comparison of the workloads of different laboratories. $^{2}$

\section{Results}

RESPONDENTS

Of the 66 questionnaires sent out, 40 (61\%) were returned. The laboratories were based in district general hospitals with bed capacities ranging from 337 to 951 (mean 594). Twenty seven $(67.5 \%)$ laboratories were based in Trust hospitals and 13 in district managed units (DMUs). Questionnaires were returned from Wales and all English regions with the exception of the West Midlands. 


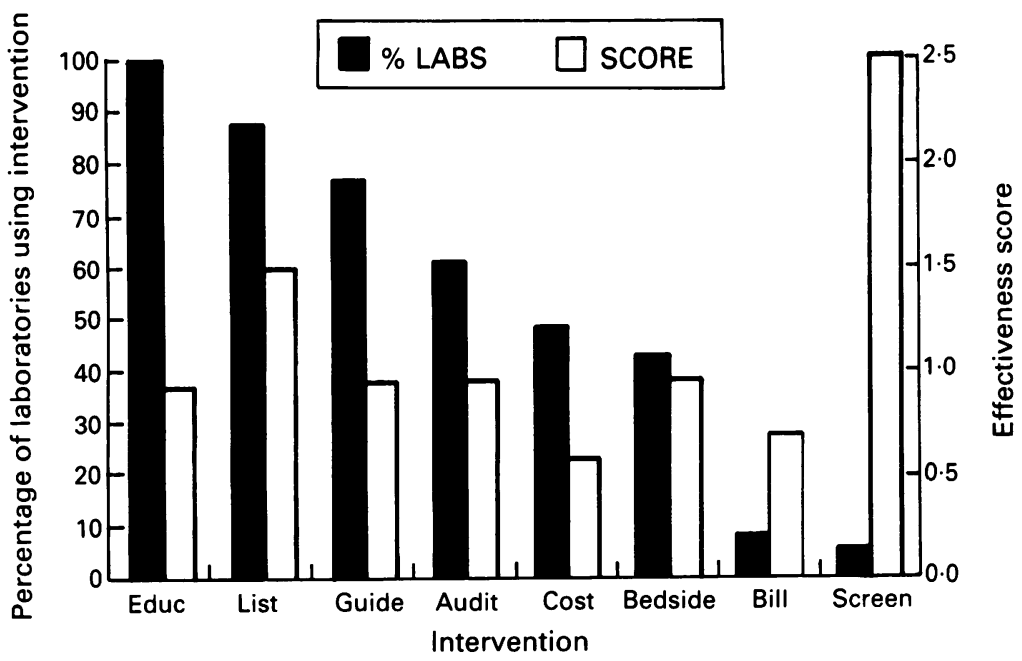

Figure 1 Use and effectiveness of strategies for reducing workload. List = provision of a limited list; guide = on-call guidelines for junior medical staff; screen = screening of calls by laboratory medical staff; audit = audit of the on-call services; cost = provision of cost information to clinicians; bill = billing of clinicians for their on-call usage; educ = education of medical staff; bedside = use of bedside testing.

\section{STRATEGIES}

Thirty eight (95\%) of the 40 respondents had attempted to reduce the out-of-hours workload. Figure 1 shows the different strategies for reduction of workload, the percentage of laboratories using these strategies, and their perceived effectiveness.

Education strategies included induction lectures (37 laboratories), other lectures $(n=$ $19)$, letters or circulars $(n=26)$, and personal or telephone contact with junior doctors and consultants $(n=9)$. Frequency of audit of the on-call services varies widely from never ( $n=17)$, once only $(n=10)$, occasionally $(n=4)$, annually $(n=3)$, twice yearly $(n=3)$, to monthly $(n=3)$.

Provision of cost information to clinicians varies from never (22 laboratories) to monthly $(n=9)$, annually $(n=2)$, once $(n=4)$ and irregularly $(n=2)$. Two laboratories provided clinicians with workload statistics but not costs. Clinical budgeting had been used by only three laboratories and had been abandoned by one of them as it had not proved worthwhile.

Where specified, bedside testing included use of glucose meters, blood gas analysers and electrolyte analysers. The latter two were usually based on the intensive care unit or special care baby unit.

Screening of requests by laboratory consultants was intermittent in one laboratory (10 days a month). Although this method was seldom used (two laboratories) it was considered highly effective in reducing workload, particularly with continuous screening.

\section{ON-CALL ARRANGEMENTS}

Nine laboratories operated an extended working day, with hours ranging from nine to 13 . There were no laboratories with 24 hour shift systems. Twenty eight of $39(72 \%)$ respondents were not satisfied with their current oncall arrangements. An extended working day was the most popular change that $82 \%$ of dissatisfied respondents would have liked to introduce. Sixty one per cent would also have liked to introduce an extended working week. Sixteen $(57 \%)$ wanted to reduce costs. Ten (36\%) wanted to introduce fixed sessional payments. This included one laboratory wanting to extend existing fixed sessional payments to include microbiology.

Only three laboratories operated multidisciplinary on-call. Eleven $(30 \%)$ of the other laboratories would have liked to introduce this. Of those laboratories without multidisciplinary on-call, 20 felt that they had insufficient qualified staff, 19 felt that the workload was too high, 14 felt that a poorer service would result, 13 felt that staff would be unwilling to provide multidisciplinary cover, three sites had consultants who objected to staff from other disciplines covering their own department, and one laboratory department was on a different site from the others.

Eight $(20 \%)$ of the dissatisfied laboratories would have liked to introduce a 24 hour shift system. Eight $(20 \%)$ of the dissatisfied laboratories would have liked to introduce a single on-call service for their district.

Five laboratories had considered competitive tendering of their on-call services. In one case this was because of difficulties in maintaining the service on a voluntary basis. In the other four cases the reasons included the need to reduce costs and to facilitate negotiation. Two laboratories had abandoned competitive tendering as a result of improved negotiations with staff. None of the respondents had ever put their on-call services out to tender.

\section{ON-CALL COSTS}

Twenty one laboratories gave information on on-call costs and total staffing costs (excluding medical, secretarial, and ancillary staff). On-call costs ranged between $10-21 \%$ of staff costs for $86 \%$ of laboratories (range 10.9 $42.4 \%$; mean $18.7 \%$ ) (fig 2 ). Only three laboratories had on-call costs outside this range $(25 \cdot 2 \%, 31 \cdot 1 \%$, and $42 \cdot 4 \%$, respectively).

In two cases the budget allowed for on-call did not reflect the expenditure, laboratories being budgeted for only $65 \%$ and $82 \%$ of their actual on-call costs. This represented an underfunding of $£ 77000$ and $£ 41577$, respectively. These laboratories had on-call costs amounting to less than $20 \%$ of the total staff costs.

Seventy per cent of respondents felt that they had been under pressure to reduce costs over the past year. This comprised $92 \%$ of DMU laboratories and 59\% of Trust hospital laboratories. Forty six per cent of DMU laboratories were operating their on-call services under Whitley Council terms, compared with $37 \%$ of the Trust status hospitals. However, DMUs had average on-call costs of $16.7 \%$ of their staff budget compared with $18.7 \%$ for all laboratories.

ON-CALL STAFF

Numbers of staff participating in the on-call for each laboratory ranged from six to 51 


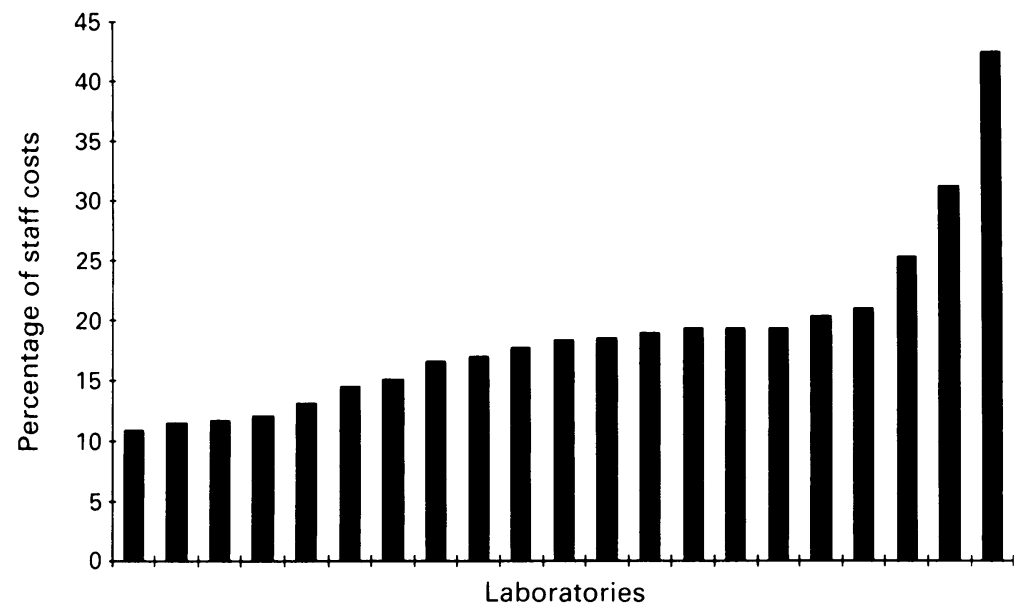

Figure 2 On-call costs shown as a percentage of total staff costs.

(average 25). Two (5\%) out of the 40 laboratories had waiting lists for MLSOs wishing to join one or more of their on-call rotas. Fourteen (35\%) laboratories reported a shortage of staff available for on-call due to having insufficient qualified staff (11 laboratories), insufficient pay $(n=3)$, and domestic and safety reasons for female staff $(n=1)$.

Thirty five $(87.5 \%)$ laboratories employed only MLSOs for the on-call work. Three laboratories also included biochemists on the on-call rota. One included junior doctors on occasion. Another laboratory included medical laboratory assistants (MLAs) if they had been trainee MLSOs before the regrading exercise of 1989. Five laboratories had employed staff to work solely during the outof-hours period. Numbers employed in this way ranged from one to four. No laboratories had staff on annual hours contracts.

\section{PAYMENT SYSTEM}

Thirty one $(78 \%)$ laboratories gave staff time off the day after a night on-call. Twenty $(65 \%)$ allowed half a day, eight allowed less than 2.5 hours, and three allowed one day off. Two laboratories allowed time off, conditional on work being performed after midnight-for example, more than three calls.

Ten $(25 \%)$ out of 40 laboratories used the Whitley Council system of payment. Two laboratories also had agreements outside Whitley Council for biochemistry and haematology, but used Whitley Council agreements for microbiology.

Thirty (75\%) laboratories had non-Whitley on-call arrangements. Of the 24 laboratories stating the amounts paid under these agreements, only seven paid standbys. None paid rates which varied according to the number of patient requests per night although workload may have been taken into account at the time of the agreement and at its annual reviews. Ten laboratories paid sessional rates (one with standby); five paid hourly rates (one with standby); five paid standby plus calls and four paid by calls only. Where payment was given as a number of Whitley Council calls, the number of calls for weeknights varied from seven to 18 per session.

Weeknight payments for biochemistry oncall were calculated per session, including standby payments. Payments per weeknight varied from $£ 104.08$ to $£ 255.00$ (average $£ 155 \cdot 14)$. As the number of hours per week night varied from 14 to 16 hours, an hourly rate of pay was calculated and ranged from $£ 6.71$ to $£ 17.00$ (average $£ 9.94$ ). This compared with daytime hourly rates of pay as follows; MLSO grade 1, $£ 6.07$; MLSO grade 2, $£ 8 \cdot 31$; MLSO grade $3, £ 10 \cdot 52$. Hourly rates of pay for haematology were the same as those for biochemistry with only two exceptions. Saturday hourly rates averaged at 1.35 times week night rates and Sunday hourly rates averaged at 1.29 times week night rates.

Eight laboratories gave rates of pay for microbiology. Two paid microbiology on-call staff under the Whitley Council system. Rates of pay for microbiology varied from $£ 24$ to $£ 117$ per night (average $£ 62$ ). Hourly rates of pay ranged from $£ 1.50$ to $£ 7.34$ per hour (average $£ 3.92$ ), presumably reflecting the lower on-call workload for this discipline.

\section{Discussion}

The most striking finding was the high proportion $(75 \%)$ of laboratories that have negotiated agreements outside Whitley Council regulations. This probably reflects the obsolescence of an agreement which was reached more than 20 years ago and has remained unchanged despite the changes in technology and workload. A wide variety of agreements has resulted, some retaining elements of Whitley Council regulations. One notable effect is that all negotiated agreements are based on fixed payments and do not have a workload-dependent component. This allows for accurate prediction of annual costs and better management of the on-call budget and consequently the total laboratory budget. However, several laboratories reported that they review their agreements on an annual basis to allow for any increases in workload. This is understandable when workload is low and consequently payments are low-for example, microbiology on-call. However, when rates of pay for out-of-hours work are considerably higher than daytime rates, perhaps there should be a threshold above which rates of pay do not rise in proportion to workload, just as daytime pay is not altered to reflect workload. Instead consideration should be given to the use of improved technology, workload reduction or, if necessary, increased numbers of staff.

It is also interesting to note that $72 \%$ of respondents were not satisfied with their oncall service, particularly with respect to the desire to introduce the extended working day. The extended working day would enable laboratories to cope with the increased workload at the end of the day, remove the 5 o'clock phenomenum, and enable laboratories to provide an improved service for GPs 
during their evening surgeries. The latter is especially important with the need to satisfy GP fundholder requirements. It may be argued that the level of satisfaction with the on-call service was found to be low because those who were satisfied with their on-call services would be less inclined to respond to the questionnaire.

Only three laboratories operated multidisciplinary on-call. Although the most commonly given reason for this was the lack of qualified staff, this problem might be overcome by training. High workload may not be sustained throughout the night, particularly after midnight, in which case multidisciplinary on-call with fewer members of staff could be more cost-effective. With the increasing pressure on laboratory budgets the choice may have to be made between continuing an underused single discipline on-call service and changing to a partly multidisciplinary service which will release savings to be spent on other service developments which would otherwise be unattainable.

The most highly scored strategy for reducing workload was that of screening calls. However, this was the least preferred strategy. This probably reflects the amount of time and effort required by consultant pathologists. The study concentrated exclusively on district general hospitals which do not have many medical staff at junior or senior grades. Also, this level of intervention may not be perceived as worthwhile because reduction of workload does not necessarily result in an equivalent reduction in costs. ${ }^{25}$

Although education of medical staff was the most preferred strategy for reduction of workload, it did not score very highly for effectiveness. This would concur with published articles which have found that teach-ins are not the most effective means of reducing workload. Chart review and audit have been reported as being more effective ${ }^{712}$ and this was confirmed by the scores. However, despite the requirement for medical staff to participate in monthly audit meetings, the on-call services did not seem to be a popular target for audit, despite the acknowledged misuse of the service and the large sums of money involved. This may be because consultants in district general hospitals, particularly those who are single-handed, find it difficult to spare the time required for regular reviews.

Provision of cost information to clinicians scored poorly. This may reflect the low commitment of clinicians to the reduction of the on-call workload. It was more surprising that the few attempts at reduction of workload by billing clinicians had apparently failed. Several papers have confirmed the importance of the active involvement of senior medical staff if any strategies for reducing workload are to be successful. ${ }^{8}$ 10-12 25 The failure of billing to produce an effect may reflect lack of interest by the clinicians who may feel that the effort required is not worthwhile for the reward. Also, in some hospitals, consultants are not on-call with their own junior medical staff. Therefore the potential for education is much reduced.

The use of a limited list is a simple intervention and yet it scored highly and was used by many laboratories. The use of more detailed guidelines scored less well. This may be because: they are less rigid in their interpretation; they are not user friendly; they are ignored by junior doctors; or that they are not reinforced by audit.

Bedside testing was reported to have been successful, although this was mainly limited to high dependency units. The questionnaire did not elicit which groups of staff were responsible for bedside testing. Recent emphasis has been on reducing rather than increasing the intensity of the junior doctors' workload. Therefore, bedside testing may have to be undertaken by other groups of staff.

Several laboratories reported a shortage of MLSOs for their on-call rota due to insufficient numbers of qualified staff. Contract staff had been employed to perform on-call work in five instances. This factor is important to bear in mind with the increasing employment of MLA in place of MLSO staff. The extended working day may help to resolve this problem if MLAs are able to work under the supervision of MLSO staff, while the number of on-call hours are reduced. Alternatively, more contract staff may need to be employed to cover the out-of-hours period.

Whichever method of reorganisation is employed it is essential that accurate costing is undertaken beforehand, including the costs of providing time off the following day which may be quite substantial.

No laboratories had a 24 hour shift system in operation, although $20 \%$ of dissatisfied laboratories felt that they would like to introduce such a system. Presumably most district general hospitals do not have sufficiently high workloads to warrant the introduction of such intensive around the clock cover.

No laboratories had staff on annual hours contracts, although some laboratories had employed contract staff to cover the on-call period. The reasons for not using annual hours contracts were not ascertained in the questionnaire. However, these may include lack of awareness of this option, or the lack of information technology, or the absence of sufficient numbers of a good mix of staff.

In two cases laboratories were grossly underfunded for their on-call services, despite apparently acceptable on-call costs. These budget holders are faced with an unattainable limit on their on-call expenditure at the start of the financial year. Savings must then be made in other areas of the budget. However, achievement of savings in the order of $£ 77000$ and $£ 41577$ would be an impossible task for most laboratories if reasonable standards are to be maintained.

In summary, most district general hospital laboratories have already started to tackle the problem of cost-control of out-of-hours services by a mixture of workload reduction strategies and by a wide variety of local agreements outside Whitley Council. This trend is 
likely to continue with the increasing pressure to contain laboratory budgets despite the ever increasing demand on these services.

I thank all those who completed and returned the questionnaire.

1 The Audit Commission. The Pathology Services. A Management Review. London: HMSO, 1991

2 Fleming PR, Zilva JF. Work-loads in chemical pathology: too many tests? Health Trends 1981;13:46-9.

3 Young DW. Improving laboratory usage: a review. Postgrad Med $\mathcal{F}$ 1988;64:283-9.

4 Stilwell A, Young D, Cunnington A. Evaluation of laboratory tests in hospitals. Ann Clin Biochem 1980;17:281-6.

5 van Heyningen C, Simms P. Guidelines for out-of-hours clinical chemistry investigations. Clin Chem 1990;36: 2151-2.

6 Sandler G. Do emergency tests help in the management of acute medical admissions? $\mathrm{Br} M$ ed $\mathcal{\Im}$ 1984;289:973-7.

7 Martin AR, Wolf MA, Thibodeau LA, Dzau V, Braunwald E. A trial of two strategies to modify the test-ordering behavior of medical residents. $N$ Engl $\mathcal{F}$ Med 1980;303 $1330-6$.

8 Anonymous. Pathology tests-too much of a good thing. [Editorial.] Lancet 1984; i:1278.

9 Gyde OHB, Leyland MJ. Reducing the use of laboratory tests. $B r$ Med $₹$ 1986;292:1462.

10 Schroeder SA, Myers LP, McPhee SJ, et al. The failure of physician education as a cost containment strategy. physician education as

11 Bareford $D$, Hayling $A$. Inappropriate use of laboratory services: long term combined approach to modify

12 Everett GD, deBlois S, Chang PF, Holets T. Effect of cost education, cost audits, and faculty chart review on the use of laboratory services. Arch Int Med 1983;143:942-4.

13 Rhyne RL, Gehlbach SH. Effects of an educational feed- back strategy on physician utilization of thyroid function panels. If Family Pract 1979;8:1003-7.

14 Watts E. Controlling demand for haematology tests. The Clinician in Management 1993;2:2-5.

15 Bhatnagar D, Weinkove C, McMurray JR. Suggested guidelines for the use of emergency tests in clinical biochemistry. $\mathcal{F}$ Clin Lab Anal 1989;3:196-8.

16 McKee M, Priest P, Ginzler M, Black N. Achieving consensus on out-of-hours laboratory tests. Ann Clin Biochem 1992;29:214-9.

17 Fraser CG, Woodford FP. Strategies to modify the testrequesting patterns of clinicians. Ann Clin Biochem 1987 requesting pat

18 Lester E. Out-of-hours laboratory investigations. Lancet 1985;ii:500.

19 Gama R, Nightingale PG, Broughton PMG, et al. Feedback of laboratory usage and cost data to clinicians does it alter requesting behaviour? Ann Clin Biochem 1991;28:143-9.

20 Gama $R$, Nightingale PG, Broughton PMG, et al. Modifying the request behaviour of clinicians. $F$ Clin Pathol 1992;45:248-9.

21 Mitchell MW, Fowkes FGR. Audit reviewed: does feed back on performance change clinical behaviour? $\mathcal{F}$ Roy Coll Phys (Lond) 1985;19:251-4.

22 Morgan DB, Gunn IR, Faye S, Clegg G, Grant AM. A comparison of alternative arrangements for an out-ofhours chemical pathology service. Lancet 1985;i:859-61. 23 Watson D. Analytical investigations closer to the patient $\mathrm{Br}$ Med $\dot{f} 1980 ; 2: 31-5$

24 Smith JM, Guest MT. "On-call"-the Croydon solution Ann Clin Biochem 1987;24(suppl 1):56-7

25 Smith ADS, Shenkin A, Dryburgh FJ, Morgan HG. Emergency biochemistry services-are they abused? Ann Clin Biochem 1982;19:325-8.

26 Gunn IR, Little AJ, Payne RB. Effects of workload and analysis time on the cost of out-of-hours investigations. analysis time on the cost of out-o

27 Lester E. A new strategy for out-of-hours laboratory investigations. Ann Clin Biochem 1986;23:497-500

28 NHS Management Executive. Changing labour utilisation in NHS Trusts. The reprofiling paper. 3rd edn. London 1992. 